Berg, J.F. van den, Kok, R.M., Marwijk, H.W.J. van, Mast, R.C. van der, Naarding, P., Oude Voshaar, R.C., Stek, M.L., Verhaak, P.F.M., Waal, M.W.M. de, Comijs, H.C. Correlates of alcoh6I abstinence and at-risk alcohol consumption in older adults with depression: the NESDO Study.7 American Journal of Geriatric Psychiatry: 2014, 22(9), 886-874

\begin{tabular}{|l|l|}
\hline $\begin{array}{l}\text { Postprint } \\
\text { Version }\end{array}$ & 1.0 \\
\hline Journal website & $\underline{\text { http://linkinghub.elsevier.com/retrieve/pii/S1064748113002145 }}$ \\
\hline Pubmed link & $\underline{\text { http://www.ncbi.nlm.nih.gov/pubmed/23891365 }}$ \\
\hline DOI & 10.1016/j.jagp.2013.04.006 \\
\hline
\end{tabular}

This is a NIVEL certified Post Print, more info at http://www.nivel.eu

\title{
Correlates of Alcohol Abstinence and At-Risk Alcohol Consumption in Older Adults with Depression: the NESDO Study
}

Julia F. VAN Den Berg, Ph.D., , RoB M. KoK, M.D., Ph.D. , HARM W.J. VAn MARWIJK, M.D., Ph.D. ${ }^{\mathrm{B}}$, RoOs C. VAN DER Mast, M.D., Ph.D. ${ }^{\mathrm{C}}$, PAUl NAARding, M.D., Ph.D. ${ }^{\mathrm{D}, \mathrm{E}}$, Richard C. Oude VoshaAR, M.D., Ph.D. ${ }^{\mathrm{F}}$, MaX L. STeK, M.D., Ph.D. ${ }^{\mathrm{B}, \mathrm{G}}$, Peter F.M. VerhaAK, Ph.D. ${ }^{\text {H, I }}$, MARgot W.M. DE WAal, Ph.D.', HANNIE C. ComiJs, Ph.D. ${ }^{\text {, }}$

Objectives: To compare alcohol use between depressed and nondepressed older adults, and to investigate correlates of alcohol abstinence and at-risk alcohol consumption in depressed older adults.

Design: Cross-sectional study.

Setting: Netherlands Study of Depression in Older Persons (NESDO).

Participants: A total of 373 participants (mean [standard deviation] age: 70.6

[7.3] years; 66\% women) diagnosed with a depressive disorder, and 128 nondepressed participants.

Measurements: Alcohol use was assessed with the Alcohol Use Disorders Identification Test (AUDIT). Participants were categorized into abstainers (AUDIT score: 0), moderate drinkers (AUDIT score: 1-4), and at-risk drinkers (AUDIT score: $\geq 5$ ). Multinomial logistic regression analysis was performed with AUDIT categories as outcome, and demographic, social, somatic, and psychological variables as determinants.

Results: The depressed group consisted of $40.2 \%$ abstainers, $40.8 \%$ moderate drinkers, and $19.0 \%$ at-risk drinkers. The depressed participants were more often abstinent and less often moderate drinkers than the nondepressed participants; they did not differ in at-risk drinking. Depressed abstainers more often used benzodiazepines but less often used antidepressants, and they had a poorer cognitive function than depressed moderate drinkers. Depressed at-risk drinkers were more often smokers and had fewer functional limitations but more severe depressive symptoms than depressed moderate drinkers.

Conclusions: Although alcohol abstinence was more common in depressed than in nondepressed older adults, $19 \%$ of depressed persons were at-risk drinkers. Because at-risk drinking is associated with more severe depression and may 
Berg, J.F. van den, Kok, R.M., Marwijk, H.W.J. van, Mast, R.C. van der, Naarding, P., Oude Voshaar, R.C., Stek, M.L., Verhaak, P.F.M., Waal, M.W.M. de, Comijs, H.C. Correlates of alcoh6I abstinence and at-risk alcohol consumption in older adults with depression: the NESDO Study. American Journal of Geriatric Psychiatry: 2014, 22(9), 886-874

have a negative impact on health and treatment outcome, it is important that physicians consider alcohol use in depressed older adults.

Depression has consistently been identified as a risk factor for, as well as a consequence of, excessive alcohol consumption or alcohol dependence. ${ }^{1}$ In addition to causal relationships in either direction, shared genetic and environmental risk factors for depression and alcohol-related problems may partly explain the frequent co-morbidity. ${ }^{2 \text { and } 3}$ The co-occurrence of depression and excessive alcohol use has negative consequences for treatment outcome, ${ }^{4}$ and it increases the risk of other unfavorable mental and physical health outcomes. ${ }^{1}$ It is very likely that this finding is particularly pertinent for older adults. As a result of changes in body composition, metabolism, and risk factors such as somatic morbidity and medication use, older adults are particularly vulnerable to the negative effects of excessive alcohol use. ${ }^{5}$

In addition to excessive alcohol use, abstinence from alcohol has been associated with depression, ${ }^{6}$ and 7 as well as with other unfavorable health parameters and mortality. ${ }^{8 \text { and } 9}$ However, abstinence from alcohol is rather a consequence than a cause of poor mental and physical health, particularly in older adults. Therefore, older adults who abstain from alcohol should be investigated as a distinct category. Studies in older adults have reported a wide range of determinants of excessive alcohol consumption, including demographic characteristics (e.g., male gender), social characteristics (e.g., higher social status, living alone), somatic characteristics (e.g., smoking, better health status), and psychological symptoms (e.g., anxiety). ${ }^{8,}$, 11,12 and 13 Childhood trauma was shown to be associated with an increased risk of self-reported alcohol problems in a recent large study among participants of a medical care program. ${ }^{14}$

Studies of patterns of alcohol consumption have not yet specifically focused on older patients with depression. Therefore, the goal of the current study was to investigate the frequency of alcohol abstinence, moderate alcohol consumption, and at-risk alcohol consumption in depressed older adults compared with nondepressed older adults. Because both excessive alcohol consumption and abstinence have been associated with depression in previous literature, ${ }^{1,6}$ and 7 we expected relatively more at-risk drinking as well as more abstinence in the depressed group than in the nondepressed group, and therefore we expected moderate drinking to be more common in the nondepressed group than in the depressed group. Furthermore, our goal was to investigate clinically relevant correlates of alcohol abstinence and at-risk alcohol consumption in depressed older adults. We explored various demographic, social, somatic, cognitive, and psychological characteristics that are known to be associated with alcohol consumption as possible correlates of abstinence and at-risk alcohol consumption in depressed older adults. Based on previous literature, we expected characteristics of an unfavorable nature (e.g., depressive symptoms, functional limitations) to increase the odds of abstinence and at-risk drinking and to decrease the odds of moderate drinking. 
Berg, J.F. van den, Kok, R.M., Marwijk, H.W.J. van, Mast, R.C. van der, Naarding, P., Oude Voshaar, R.C., Stek, M.L., Verhaak, P.F.M., Waal, M.W.M. de, Comijs, H.C. Correlates of alcoh6I abstinence and at-risk alcohol consumption in older adults with depression: the NESDO Study.7 American Journal of Geriatric Psychiatry: 2014, 22(9), 886-874

\section{METHODS}

\section{Setting and Participants}

The Netherlands Study of Depression in Older Persons (NESDO) is a multisite, naturalistic prospective cohort study that was designed to examine the neurobiological, psychosocial, and physical determinants, course, and consequences of depressive disorders in older persons over a period of 6 years and to compare these with those of depression earlier in adulthood. ${ }^{15}$ Between 2007 and 2010, a total of 378 depressed and 132 nondepressed older persons (60 years of age and older) were included. We diagnosed depression (major depression, dysthymia, or minor depression) with the Composite International Diagnostic Interview (World Health Organization version 2.1; lifetime version), ${ }^{16}$ according to Diagnostic and Statistical Manual of Mental Disorders, Fourth Edition (DSM-IV), criteria. Participants with depression were recruited from five regional centers for mental health care, as well as through general practitioners, in The Netherlands; nondepressed participants were recruited in the same general practices as the depressed participants, by approaching a random selection of persons who were screened negative for depression (a score $<4$ on the 15 -item Geriatric Depression Scale ${ }^{17}$ ). Exclusion criteria for both groups were a Mini-Mental State Examination (MMSE) ${ }^{18}$ score $<18$ and insufficient command of the Dutch language. The baseline assessment included written questionnaires, interviews, and physical assessments. A more detailed description of the recruitment of depressed and nondepressed participants of the NESDO study and the assessment procedures was published by Comijs et al. ${ }^{15}$

We compared the prevalence of abstinence from alcohol and of moderate and at-risk drinking between depressed and nondepressed older adults. Because alcohol use in older adults with depression was our main subject of interest, correlates of abstinence and at-risk alcohol use were explored in the depressed participants only. Five depressed and four nondepressed participants were excluded because of incomplete data on their alcohol use, which resulted in 373 depressed and 128 nondepressed older adults being included in our study.

\section{Measures}

The following characteristics were included in our analysis: gender, age, and income (as a proxy measure for socioeconomic status), living alone, social support (operationalized as having $\geq 2$ confidants) and the size of the social network, smoking, functional limitations and the number of chronic diseases (as two different measures of general physical health), anxiety, severity of depressive symptoms, and childhood trauma. We also included cognitive function (because poor cognitive functioning can be a consequence of excessive alcohol use as well as a reason to abstain from alcohol) and insomnia, because this can lead to drinking alcohol as a form of self-medication and it can also be a consequence of excessive alcohol use. The use of antidepressants was included because we assumed that treatment recommendations would lead to an association with abstinence; frequent use of benzodiazepines was included because this is common in depressed older adults and could have unwanted interactions with at-risk alcohol use. We studied loneliness as a 
Berg, J.F. van den, Kok, R.M., Marwijk, H.W.J. van, Mast, R.C. van der, Naarding, P., Oude Voshaar, R.C., Stek, M.L., Verhaak, P.F.M., Waal, M.W.M. de, Comijs, H.C. Correlates of alcoh6I abstinence and at-risk alcohol consumption in older adults with depression: the NESDO Study. American Journal of Geriatric Psychiatry: 2014, 22(9), 886-874

separate variable because this is a distinct concept from depressive symptoms and actual perceived social support or the social network, with its own health-related risks and outcomes, ${ }^{19}$ and we were interested in its association with alcohol consumption.

The demographic, social, somatic, and psychological variables for our analyses were obtained by written questionnaires and interviews of the NESDO baseline assessment. We assessed alcohol consumption by using the Alcohol Use Disorders Identification Test (AUDIT), a questionnaire consisting of 10 items with a minimum score of 0 and a maximum score of $40 .^{20}$ The AUDIT was shown to be a suitable instrument to detect at-risk drinking in community-dwelling older adults aged 65-74 years, with a cutoff score of 5 (sensitivity: 0.86; specificity: 0.87 ). ${ }^{21}$ This cutoff score was also recommended for older adults by the Dutch multidisciplinary guideline for treatment of alcohol-related problems. ${ }^{22}$ Participants who answered "never" to the first question of the AUDIT (whether they ever drink alcohol) obtained an AUDIT score of 0 and were categorized as "abstainers"; those with an AUDIT score of 1-4 were "moderate drinkers"; and those with an AUDIT score $\geq 5$ were "at-risk drinkers." The total AUDIT score encompasses not only the volume and frequency of alcohol use but also other drinking behavior risks.

Gender, age, income, living alone (yes/no), and smoking were assessed by using standard questions. For income, we calculated tertiles for the overall study sample and created the income categories "low," "middle," and "high” accordingly.

Social support and the size of social network were measured with an abbreviated version of the Close Person Inventory. ${ }^{23}$ We operationalized "social support” as having at least two persons one feels connected to or who give emotional/practical support when necessary ("confidants"). These two persons may include a spouse or partner. The size of the social network was based on the question "with how many persons do you have regular and meaningful contact (children and persons who live in the same house excluded)?”

We asked participants to bring the medication they used to the interview; this medication was registered by the interviewer, and participants were asked whether they used each medicine frequently or infrequently. Antidepressants were always taken frequently, but benzodiazepines were sometimes used only occasionally. We categorized participants into "frequent benzodiazepine users" versus "no/occasional benzodiazepine users.”

Self-reported functional limitations were assessed by using the WHO-Disability Assessment Schedule (WHO-DAS). ${ }^{24}$ To calculate the score on the WHO-DAS, we omitted items related to work because of the age of the participants. To evaluate the presence of chronic diseases, we asked participants whether they had any of the following chronic diseases or events: cardiac disease, peripheral atherosclerosis, stroke, diabetes mellitus, chronic obstructive pulmonary disease, arthritis, cancer, or any other disease. ${ }^{25}$ 
Berg, J.F. van den, Kok, R.M., Marwijk, H.W.J. van, Mast, R.C. van der, Naarding, P., Oude Voshaar, R.C., Stek, M.L., Verhaak, P.F.M., Waal, M.W.M. de, Comijs, H.C. Correlates of alcoh6I abstinence and at-risk alcohol consumption in older adults with depression: the NESDO Study American Journal of Geriatric Psychiatry: 2014, 22(9), 886-874

Cognitive function was assessed by using the MMSE. ${ }^{18}$ This instrument has a range of $0-30$, but an MMSE score <18 was an exclusion criterion for this study; a higher MMSE score indicates better cognitive functioning. We assessed severity of depressive symptoms with the 30-item self-report version of the Inventory of Depressive Symptoms-Self-Report (range: $0-84),{ }^{26}$ anxiety symptoms with the Beck Anxiety Inventory (range: $0-63),{ }^{27}$ insomnia with the Women's Health Initiative Insomnia Rating Scale (range: 0-20), ${ }^{28,29}$ and 30 and loneliness with the Loneliness and Affiliation Scale (range: 0-11). ${ }^{31}$ and 32 For childhood trauma, a Childhood Trauma Index was calculated, as was done previously in the The Netherlands Mental Health Survey and Incidence Study (NEMESIS) (range: $0-4) .{ }^{33}$ For all of these instruments except the MMSE, a higher score indicates more symptoms or higher severity.

\section{Statistical Analysis}

The depressed and nondepressed participants were categorized as abstainers, moderate drinkers, or at-risk drinkers. We compared the distribution of participants into the three categories between depressed and nondepressed participants with a cross-tabulation with Pearson's $\chi^{2}$ test. The significant result of the $\chi^{2}$ test was explored in more detail with pairwise comparisons of the proportions ( $z$ test) with Bonferroni correction.

We next summarized the data for the depressed participants in each of the three alcohol consumption groups. Unadjusted differences were calculated between these groups, with analysis of variance (ANOVA) for continuous variables and Pearson's $\chi^{2}$ tests for categorical variables. To explore which of the three groups differed significantly from each other, the significant results of the ANOVAs were explored in more detail with post hoc tests; Hochberg GT2 tests were used because the group sizes were different. The significant results of the $\chi^{2}$ tests were explored in more detail as described earlier.

The following variables had missing values: living alone $(\mathrm{n}=1)$, social support $(\mathrm{n}=$ $1)$, smoking $(n=3)$, functional limitations $(n=10)$, number of chronic diseases $(n=$ $1)$, cognitive function $(n=1)$, severity of depressive symptoms $(n=1)$, anxiety symptoms $(n=25)$, insomnia $(n=14)$, loneliness $(n=24)$, and childhood trauma $(n=$ 3). These missing values were imputed with multiple imputation based on linear regression; all of the independent variables were used as predictor variables for the imputation.

To check for possible collinearity, the correlation matrix of all of the continuous variables was explored, as were the collinearity statistics of a linear regression model with all of the continuous independent variables. Finally, we investigated the associations between the possible determinants and categories of alcohol consumption with a multinomial logistic regression analysis. Because this was an explorative analysis, we initially entered all of the variables into the model, including the variables that were not significantly associated with alcohol consumption in the univariate analyses because the results of univariate analyses may be affected by 
Berg, J.F. van den, Kok, R.M., Marwijk, H.W.J. van, Mast, R.C. van der, Naarding, P., Oude Voshaar, R.C., Stek, M.L., Verhaak, P.F.M., Waal, M.W.M. de, Comijs, H.C. Correlates of alcoh6I abstinence and at-risk alcohol consumption in older adults with depression: the NESDO Study. American Journal of Geriatric Psychiatry: 2014, 22(9), 886-874

confounding. To nevertheless obtain a parsimonious model, a backward stepwise procedure of variable selection was applied. We used the moderate drinking category as a reference category. The pooled results after the multiple imputation are reported. Statistical analyses were performed by using SPSS version 20 for Windows (IBM SPSS Statistics, IBM Corporation, Armonk, New York).

\section{RESULTS}

In this study sample of 373 depressed older adults, $66.0 \%$ were women, the mean (standard deviation) age was 70.6 (7.3) years, and the age range was 60-90 years. In the nondepressed group $(\mathrm{n}=128), 61.7 \%$ were women, and the mean age was 69.9 (7.1) years, which was not significantly different from the depressed group (gender: $\chi^{2}=0.749, d f=1, \mathrm{p}=0.39$; age: $t=-0.92, d f=499, \mathrm{p}=0.36$ ).

Of the depressed participants $(\mathrm{n}=373), 150(40.2 \%)$ were classified as abstainers, $152(40.8 \%)$ as moderate drinkers, and $71(19.0 \%)$ as at-risk drinkers. In the nondepressed group $(\mathrm{n}=128), 17(13.3 \%)$ persons were abstainers, $80(62.5 \%)$ persons were moderate drinkers, and 31 (24.2\%) persons were at-risk drinkers. Cross-tabulation showed that the distribution of the three categories was significantly different for the depressed group and the nondepressed group $\left(\chi^{2}=31.7, d f=2, \mathrm{p}\right.$ $<0.001)$. Pairwise comparisons with Bonferroni correction revealed that abstinence was more frequent in the depressed group than in the nondepressed group, and moderate drinking was more frequent in the nondepressed group than in the depressed group. The proportion of at-risk drinkers was not significantly different between the two groups.

The characteristics of the depressed group and the unadjusted differences between the three subgroups are shown in Table 1 . The results of the univariate post hoc Hochberg GT2 tests, performed for each of the significant ANOVAs (continuous variables), as well as the results of the $\chi^{2}$ tests and pairwise comparisons with Bonferroni correction for the results with significant $\chi^{2}$ tests (categorical variables) showed that at-risk drinkers were more often male than abstainers, but the percentages of men in these groups did not differ significantly from the percentage of men among moderate drinkers. At-risk drinkers were significantly younger than either of the other two groups. Both abstainers and at-risk drinkers had less social support than moderate drinkers. Abstainers were more likely to frequently use benzodiazepines than the other two groups. At-risk drinkers were more likely to smoke than the other two groups. Abstainers had more functional limitations and more chronic diseases than moderate drinkers, poorer cognitive function than moderate drinkers and at-risk drinkers, and more severe depressive symptoms and more insomnia than moderate drinkers. At-risk drinkers had a higher childhood trauma index than abstainers.

\section{[TABLE 1]}

No significant differences between the groups were apparent in post hoc tests for anxiety symptoms and loneliness. To adjust for possible confounding, we performed 
Berg, J.F. van den, Kok, R.M., Marwijk, H.W.J. van, Mast, R.C. van der, Naarding, P., Oude Voshaar, R.C., Stek, M.L., Verhaak, P.F.M., Waal, M.W.M. de, Comijs, H.C. Correlates of alcoh6I abstinence and at-risk alcohol consumption in older adults with depression: the NESDO Study. American Journal of Geriatric Psychiatry: 2014, 22(9), 886-874

a multinomial logistic regression analysis, after multiple imputation of missing values. Because no collinearity among the independent variables was detected, we initially entered all of the variables into the model.

After the backward stepwise regression, a pooled model could not be calculated because the model parameters varied by imputation. Specifically, "loneliness" was eliminated as a model parameter in four of the imputations but not in one other imputation. Age, income category, living alone, size of social network, number of chronic diseases, anxiety symptoms, and insomnia were consistently excluded from the model in all imputations. Table 2 presents a final model with the remaining parameters, excluding loneliness.

\section{[TABLE 2]}

According to the multivariate model, abstainers from alcohol were more than twice as likely as moderate drinkers to frequently use benzodiazepines but only one-half as likely to use antidepressants. Abstainers had poorer cognitive function than moderate drinkers.

Compared with moderate drinkers, at-risk drinkers were more often smokers, had fewer functional limitations, and had more severe depressive symptoms. Both abstainers and at-risk drinkers had significantly less social support (i.e., were less likely to have $\geq 2$ confidants) than moderate drinkers. None of the other variables was significantly associated with alcohol consumption in this multivariate model.

\section{CONCLUSIONS}

In this cross-sectional study of 373 depressed older adults, $19 \%$ of the participants were at-risk drinkers, $41 \%$ were moderate drinkers, and $40 \%$ abstained from alcohol. Abstinence from alcohol was more common in this depressed group than in the group of nondepressed older adults, whereas moderate drinking was more common in the nondepressed group. These findings are in line with our hypotheses. We had also expected at-risk drinking to be more common in the depressed group than in the nondepressed group; this hypothesis was not confirmed by the data. This finding may be explained in part by the rather conservative cutoff score we used for at-risk drinking and the underrepresentation of persons with severe alcohol-related problems in our study sample.

In the multivariate analyses, several correlates of abstinence and of at-risk drinking were identified. Abstainers from alcohol were considerably more often regular benzodiazepine users than moderate drinkers. Possibly, unwanted interactions cause regular benzodiazepine users to abstain from alcohol. However, abstainers were less likely to use antidepressants than moderate drinkers. This contrast warrants further study. Do these patients receive inadequate treatment for their depression (benzodiazepines rather than antidepressants) or do they have other reasons (e.g., medical contraindications) to use more benzodiazepines and fewer antidepressants? Another finding of concern is that using antidepressants did not decrease the 
Berg, J.F. van den, Kok, R.M., Marwijk, H.W.J. van, Mast, R.C. van der, Naarding, P., Oude Voshaar, R.C., Stek, M.L., Verhaak, P.F.M., Waal, M.W.M. de, Comijs, H.C. Correlates of alcoh6I abstinence and at-risk alcohol consumption in older adults with depression: the NESDO Study.7 American Journal of Geriatric Psychiatry: 2014, 22(9), 886-874

likelihood of at-risk drinking, whereas the use of alcohol, even moderate use, could decrease the effectiveness of pharmacologic antidepressant treatment ${ }^{34}$ and, inversely, decreasing alcohol consumption can be beneficial to the treatment of depression among older patients. ${ }^{4}$

Furthermore, depressed abstainers had less social support than depressed moderate drinkers, which could be related to the absence of "social drinking" and therefore with abstinence. Several studies have shown that participation in social activities and drinking for social reasons is associated with more alcohol consumption. ${ }^{35}$ and 36

Our study also demonstrated that depressed abstainers had a poorer cognitive function than depressed participants with moderate or at-risk alcohol use. This association may be explained by the finding that older people stop drinking alcohol when their physical or mental health deteriorates or when cognitive disorders occur, as was found in the Longitudinal Aging Study Amsterdam. ${ }^{37}$

At-risk drinking was associated with smoking, which is in line with previous findings, ${ }^{12}$ and with having fewer functional limitations (i.e., better physical health). Accordingly, in a large study among primary care patients aged 75 years and older in the United Kingdom, drinkers had a better perceived health than abstainers, along with a fairly active and sociable lifestyle. ${ }^{8}$ Similar results were found in older primary care patients in the United States ${ }^{38}$ and community-dwelling older persons in Germany. ${ }^{11}$ However, in a study that included severely alcohol-dependent participants, a negative association between self-rated health and alcohol consumption was found. ${ }^{39}$ Most likely, there is a U- or J-shaped curve between alcohol consumption and health, which means that poor health is related to abstinence as well as to excessive alcohol use. ${ }^{13,38}$ and 40 Because both at-risk drinking and abstinence were associated with less social support, the association between social support and alcohol consumption seems to be nonlinear as well, with moderate drinkers having the highest level of social support compared with abstainers and atrisk drinkers. The lower perceived social support among at-risk drinkers in our study was also reported in a large study among older primary care patients. ${ }^{10}$

The severity of depressive symptoms was higher in at-risk drinkers, compared with moderate drinkers, possibly due to a causal pathway in either direction, as previous studies suggested. ${ }^{2}$ and 3 Severe depressive symptoms may increase the risk of at-risk drinking but may also be a consequence of excessive alcohol use.

Some methodologic limitations of this study need to be discussed. We compared the frequencies of abstinence, moderate drinking, and at-risk drinking between depressed and nondepressed participants of the NESDO study. The percentages found may not necessarily reflect the occurrence in the general population because of the "healthy volunteer effect." However, this effect is likely to be equally present in both depressed and nondepressed older adults. Therefore, our conclusion that alcohol abstinence is more common in depression and moderate drinking in nondepressed older adults probably is valid for the general population. Another important limitation of our study is the absence of data on the history of alcohol consumption. 
Berg, J.F. van den, Kok, R.M., Marwijk, H.W.J. van, Mast, R.C. van der, Naarding, P., Oude Voshaar, R.C., Stek, M.L., Verhaak, P.F.M., Waal, M.W.M. de, Comijs, H.C. Correlates of alcoh6I abstinence and at-risk alcohol consumption in older adults with depression: the NESDO Study. American Journal of Geriatric Psychiatry: 2014, 22(9), 886-874

Therefore, it was impossible to distinguish lifetime abstainers from persons who used to be (heavy) drinkers and stopped drinking alcohol later in life. In addition, the cross-sectional design of our study precluded the inference of temporal or causal relationships. Finally, our findings cannot be generalized to patients with severe alcohol dependence because they were underrepresented in our study. In The Netherlands, patients with severe alcohol dependence are generally treated in specialized addiction facilities rather than in mental health care institutions.

Strengths of the study include the size of the study sample, in particular the number of depressed participants, and the extensive data collection, which allowed for a thorough explorative analysis of possible correlates and elaborate adjustment for confounding. Analyzing abstinence separately from moderate alcohol consumption is another strength of our study. Although the subgroup of abstainers in the nondepressed subgroup was relatively small, it was sufficiently large to detect that abstinence was more frequent in depressed than in nondepressed participants.

In conclusion, our study showed that although abstaining from alcohol was more common in depressed than in nondepressed older adults, 19\% of the depressed older persons were at-risk drinkers. This finding warrants attention by clinicians, as excessive drinking is associated with more severe depressive symptoms and may interfere with treatment for depression. Among depressed older persons, abstainers from alcohol used more benzodiazepines but fewer antidepressants, and had a poorer cognitive function than moderate drinkers. Depressed at-risk drinkers were more often smokers, had fewer functional limitations but more severe depressive symptoms than depressed moderate drinkers. Both abstainers and at-risk drinkers with depression had less social support than depressed moderate drinkers.

Seemingly intuitive/“classical” risk factors for excessive alcohol use, such as income, living alone, anxiety, childhood trauma, and insomnia, were unrelated to alcohol consumption in our study. Follow-up studies are necessary to investigate temporal relations and underlying mechanisms of alcohol consumption in depressed older persons and their implications for treatment.

\section{Acknowledgements}

The infrastructure for NESDO is funded through the Fonds NutsOhra, Stichting tot Steun VCVGZ, NARSAD The Brain and Behaviour Research Fund, and the participating universities and mental health care organizations (VU University Medical Center, Leiden University Medical Center, University Medical Center Groningen, Radboud University Nijmegen Medical Center, and GGZ inGeest, GGNet, GGZ Nijmegen, GGZ Rivierduinen, Lentis, and Parnassia Psychiatric Institute).

\section{REFERENCES}

1 F.C. Blow, A.M. Serras, K.L. Barry Late-life depression and alcoholism Curr Psychiatry Rep, 9 (2007), pp. 14-19 
Berg, J.F. van den, Kok, R.M., Marwijk, H.W.J. van, Mast, R.C. van der, Naarding, P., Oude Voshaar, R.C., Stek, M.L., Verhaak, P.F.M., Waal, M.W.M. de, Comijs, H.C. Correlates of alcoh6 abstinence and at-risk alcohol consumption in older adults with depression: the NESDO Study American Journal of Geriatric Psychiatry: 2014, 22(9), 886-874

2 P.H. Kuo, C.O. Gardner, K.S. Kendler, et al. The temporal relationship of the onsets of alcohol dependence and major depression: using a genetically informative study design Psychol Med, 36 (2006), pp. 1153-1162

3 D.M. Fergusson, J.M. Boden, L.J. Horwood Tests of causal links between alcohol abuse or dependence and major depression Arch Gen Psychiatry, 66 (2009), pp. 260-266

4 D.W. Oslin, I.R. Katz, W.S. Edell, et al. Effects of alcohol consumption on the treatment of depression among elderly patients Am J Geriatr Psychiatry, 8 (2000), pp. 215-220

5 D.W. Oslin Alcohol use in late life: disability and comorbidity J Geriatr Psychiatry Neurol, 13 (2000), pp. 134-140

6 B. Rodgers, A.E. Korten, A.F. Jorm, et al. Risk factors for depression and anxiety in abstainers, moderate drinkers and heavy drinkers Addiction, 95 (2000), pp. 1833-1845

7 R. Alati, D.A. Lawlor, J.M. Najman, et al. Is there really a 'J-shaped' curve in the association between alcohol consumption and symptoms of depression and anxiety? Findings from the Mater-University Study of Pregnancy and its outcomes Addiction, 100 (2005), pp. 643-651

8 S. Hajat, A. Haines, C. Bulpitt, et al. Patterns and determinants of alcohol consumption in people aged 75 years and older: results from the MRC trial of assessment and management of older people in the community Age Ageing, 33 (2004), pp. 170-177

$9 \mathrm{~J}$. Connor The life and times of the J-shaped curve Alcohol Alcohol, 41 (2006), pp. 583584

10 J.E. Kirchner, C. Zubritsky, M. Cody, et al. Alcohol consumption among older adults in primary care J Gen Intern Med, 22 (2007), pp. 92-97

11 Y. Du, C. Scheidt-Nave, H. Knopf Use of psychotropic drugs and alcohol among noninstitutionalised elderly adults in Germany Pharmacopsychiatry, 41 (2008), pp. 242-251

$12 \mathrm{~S}$. Immonen, J. Valvanne, K.H. Pitkala Prevalence of at-risk drinking among older adults and associated sociodemographic and health-related factors J Nutr Health Aging, 15 (2011), pp. 789-794

$13 \mathrm{M}$. Aartsen Substance use and abuse among older adults: a state of the art Uehara T. Rijeka (Ed.), Psychiatric Disorders-Trends and Developments, InTech, Croatia (2011), pp. 389-402

$14 \mathrm{~T}$. Strine Associations between adverse childhood experiences, psychological distress, and adult alcohol problems Am J Health Behav, 36 (2012), pp. 408-423

15 H.C. Comijs, H.W. van Marwijk, R.C. van der Mast, et al. The Netherlands study of depression in older persons (NESDO): a prospective cohort study BMC Res Notes, 4 (2011), p. 524

16 H.U. Wittchen, L.N. Robins, L.B. Cottler, et al. Cross-cultural feasibility, reliability and sources of variance of the Composite International Diagnostic Interview (CIDI). The Multicentre WHO/ADAMHA Field Trials Br J Psychiatry, 159 (1991), pp. 645-653 658

17 J.I. Sheikh, J.A. Yesavage Geriatric Depression Scale (GDS): recent evidence and development of a shorter version Clin Gerontol, 5 (1986), pp. 165-173

18 M.F. Folstein, S.E. Folstein, P.R. McHugh "Mini-mental state." A practical method for grading the cognitive state of patients for the clinician J Psychiatr Res, 12 (1975), pp. 189198

19 L.A. Theeke Sociodemographic and health-related risks for loneliness and outcome differences by loneliness status in a sample of U.S. older adults Res Gerontol Nurs, 3 (2010), pp. 113-125

20 T. Babor, J. Higgins-Biddle, J. Saunders, et al. AUDIT. The Alcohol Use Disorders Identification Test. Guidelines for Use in Primary care (2nd ed.)World Health Organisation, Geneva, Switzerland (2001)

$21 \mathrm{M}$. Aalto, H. Alho, J.T. Halme, et al. The alcohol use disorders identification test (AUDIT) and its derivatives in screening for heavy drinking among the elderly Int $\mathrm{J}$ Geriatr Psychiatry, 26 (2011), pp. 881-885

22 H. De Beer, G. Van de Glind Multidisciplinaire richtlijn Stoornissen in het gebruik van alcohol Trimbos-instituut, Utrecht, The Netherlands (2009)

23 S. Stansfeld, M. Marmot Deriving a survey measure of social support: the reliability and validity of the Close Persons Questionnaire Soc Sci Med, 35 (1992), pp. 1027-1035 
Berg, J.F. van den, Kok, R.M., Marwijk, H.W.J. van, Mast, R.C. van der, Naarding, P., Oude Voshaar, R.C., Stek, M.L., Verhaak, P.F.M., Waal, M.W.M. de, Comijs, H.C. Correlates of alcoh6I abstinence and at-risk alcohol consumption in older adults with depression: the NESDO Study.7 American Journal of Geriatric Psychiatry: 2014, 22(9), 886-874

24 L. Chwastiak, M. Von Korff Disability in depression and back pain: evaluation of the World Health Organization Disability Assessment Schedule (WHO DAS II) in a primary care setting J Clin Epidemiol, 56 (2003), pp. 507-514

25 D. Kriegsman, B. Penninx, J. van Eijk, et al. Self-reports and general practitioner information on the presence of chronic diseases in community dwelling elderly. A study on the accuracy of patients' self-reports and on determinants of inaccuracy J Clin Epidemiol, 49 (1996), pp. 1407-1417

26 A. Rush, C. Gullion, M. Basco, et al. The Inventory of Depressive Symptomatology (IDS): psychometric properties Psychol Med, 26 (1996), pp. 477-486

27 A. Beck, N. Epstein, G. Brown, et al. An inventory for measuring clinical anxiety: psychometric properties J Consult Clin Psychol, 56 (1988), pp. 893-897

28 D. Levine, R. Kaplan, D. Kripke, et al. Factor structure and measurement invariance of the Women's Health Initiative Insomnia Rating Scale Psychol Assess, 15 (2003), pp. 123136

29 D. Levine, D. Kripke, R. Kaplan, et al. Reliability and validity of the Women's Health Initiative Insomnia Rating Scale Psychol Assess, 15 (2003), pp. 137-148

30 D. Levine, M. Dailey, B. Rockhill, et al. Validation of the Women's Health Initiative Insomnia Rating Scale in a multicenter controlled clinical trial Psychosom Med, 67 (2005), pp. 98-104

31 J. De Jong Gierveld, F.H. Kamphuis The development of a Rasch-type loneliness scale Appl Psychol Meas, 9 (1985), pp. 289-299

32 J. De Jong Gierveld, T. Van Tilburg Dykstra P: Loneliness and social isolation A.

Vangelisti, D. Perlman (Eds.), Cambridge Handbook of Personal Relationships, Cambridge University Press, Cambridge (2006), pp. 485-500

33 R. De Graaf, R. Bijl, M. Ten Have, et al. Pathways to comorbidity: the transition of pure mood, anxiety and substance use disorders into comorbid conditions in a longitudinal population-based study J Affect Disord, 82 (2004), pp. 461-467

34 J. Worthington, M. Fava, C. Agustin, et al. Consumption of alcohol, nicotine, and caffeine among depressed outpatients. Relationship with response to treatment Psychosomatics, 37 (1996), pp. 518-522

35 W. Busby, A. Campbell, M. Borrie, et al. Alcohol use in a community-based sample of subjects aged 70 years and older J Am Geriatr Soc, 36 (1988), pp. 301-305

$36 \mathrm{~K}$. Graham, D. Clarke, C. Bois, et al. Addictive behavior of older adults Addict Behav, 21 (1996), pp. 331-348

$37 \mathrm{H}$. Comijs, M. Aartsen, M. Visser, et al. Alcoholgebruik onder 55-plussers in Nederland Tijdschr Gerontol Geriatr, 43 (2012), pp. 115-126

38 F.C. Blow, M.A. Walton, K.L. Barry, et al. The relationship between alcohol problems and health functioning of older adults in primary care settings J Am Geriatr Soc, 48 (2000), pp. 769-774

39 P. Sacco, K.K. Bucholz, E.L. Spitznagel Alcohol use among older adults in the national epidemiologic survey on alcohol and related conditions: a latent class analysis J Stud Alcohol Drugs, 70 (2009), pp. 829-838

40 A. Di Castelnuovo, S. Costanzo, V. Bagnardi, et al.

Alcohol dosing and total mortality in men and women: an updated meta-analysis of 34 prospective studies Arch Intern Med, 166 (2006), pp. 2437-2445 
Berg, J.F. van den, Kok, R.M., Marwijk, H.W.J. van, Mast, R.C. van der, Naarding, P., Oude

Voshaar, R.C., Stek, M.L., Verhaak, P.F.M., Waal, M.W.M. de, Comijs, H.C. Correlates of alcoh6I abstinence and at-risk alcohol consumption in older adults with depression: the NESDO Study.

American Journal of Geriatric Psychiatry: 2014, 22(9), 886-874

\section{TABLES}

Table 1.: Characteristics of the Study Population of Depressed Older Adults and Univariate Analyses $(\mathrm{N}=373)$

\begin{tabular}{|c|c|c|c|c|c|}
\hline & $\begin{array}{c}\text { Abstainers } \\
(n=150)\end{array}$ & $\begin{array}{l}\text { Moderate } \\
\text { Drinkers } \\
(n=152)\end{array}$ & $\begin{array}{l}\text { At-Risk } \\
\text { Drinkers } \\
(n=71)\end{array}$ & $\mid \begin{array}{c}\chi^{2}(d f) \text { or } \\
F(d f \\
\text { model; } \\
d f \text { error) } \\
\text { a }\end{array}$ & $\begin{array}{c}\mathbf{p} \\
\text { Value }^{\mathrm{a}}\end{array}$ \\
\hline \multicolumn{6}{|l|}{\begin{tabular}{|l}
$\begin{array}{l}\text { Demographic } \\
\text { characteristics }\end{array}$ \\
\end{tabular}} \\
\hline $\begin{array}{l}\text { Female gender, no. } \\
(\%)\end{array}$ & $110(73.3)$ & 99 (65.1) & $37(52.1)$ & $\begin{array}{l}\chi^{2}=9.7 \\
(2)\end{array}$ & 0.008 \\
\hline Age, mean (SD) & $71.3(7.4)$ & 71.2 (7.6) & $68.0(5.7)$ & $\begin{array}{l}F=5.8 \\
(2 ; 370)\end{array}$ & 0.003 \\
\hline Income, no. (\%) & & & & $\begin{array}{l}\chi^{2}=8.8 \\
(4)\end{array}$ & 0.066 \\
\hline Low & 56 (37.3) & $48(31.6)$ & $25(35.2)$ & & \\
\hline Middle & $58(38.7)$ & $48(31.6)$ & $18(25.4)$ & & \\
\hline High & $36(24.0)$ & $56(36.8)$ & $28(39.4)$ & & \\
\hline \multicolumn{6}{|l|}{\begin{tabular}{|l}
$\begin{array}{l}\text { Social variables, no. } \\
(\%)\end{array}$ \\
\end{tabular}} \\
\hline Living alone & 80 (53.7) & $80(52.6)$ & $31(43.7)$ & $\begin{array}{l}\chi^{2}=2.1 \\
(2)\end{array}$ & 0.349 \\
\hline $\begin{array}{l}\text { Social support }(\geq 2 \\
\text { confidants) }\end{array}$ & 89 (59.7) & $111(73.0)$ & $38(53.5)$ & $\begin{array}{l}\chi^{2}=9.9 \\
(2)\end{array}$ & 0.007 \\
\hline $\begin{array}{l}\text { Size of social } \\
\text { network }\end{array}$ & & & & $\begin{array}{l}\chi^{2}=9.0 \\
(4)\end{array}$ & 0.061 \\
\hline $0-1$ & $30(20.1)$ & $18(11.8)$ & $5(7.0)$ & & \\
\hline $2-5$ & $66(44.3)$ & $68(44.7)$ & $38(53.5)$ & & \\
\hline$\geq 6$ & 53 (35.6) & $66(43.4)$ & $28(39.4)$ & & \\
\hline \multicolumn{6}{|l|}{$\begin{array}{l}\text { Somatic and lifestyle } \\
\text { variables }\end{array}$} \\
\hline $\begin{array}{l}\text { Use of } \\
\text { antidepressants, no. } \\
(\%)\end{array}$ & $108(72.0)$ & 113 (74.3) & $51(71.8)$ & $\begin{array}{l}\chi^{2}=0.3 \\
(2)\end{array}$ & 0.877 \\
\hline \begin{tabular}{|l|}
$\begin{array}{l}\text { Frequent use of } \\
\text { benzodiazepines, no. } \\
(\%)\end{array}$ \\
\end{tabular} & $81(54.0)$ & $49(32.2)$ & 17 (23.9) & $\begin{array}{l}\chi^{2}=23.8 \\
(2)\end{array}$ & $<0.001$ \\
\hline Smoking, no. (\%) & 35 (23.5) & $30(20.0)$ & $33(46.5)$ & $\begin{array}{l}\chi^{2}=18.5 \\
(2)\end{array}$ & $<0.001$ \\
\hline
\end{tabular}




\begin{tabular}{|c|c|c|c|c|c|}
\hline & \begin{tabular}{|c} 
Abstainers \\
$(\mathrm{n}=150)$
\end{tabular} & $\begin{array}{l}\text { Moderate } \\
\text { Drinkers } \\
(n=152)\end{array}$ & $\begin{array}{c}\text { At-Risk } \\
\text { Drinkers } \\
(n=71)\end{array}$ & $\begin{array}{c}\chi^{2}(d f) \text { or } \\
\text { F }(d f \\
\text { model; } \\
d f \text { error }) \\
\text { a }\end{array}$ & $\underset{\text { Value }^{\mathrm{a}}}{\mathbf{p}}$ \\
\hline $\begin{array}{l}\text { Functional } \\
\text { limitations, WHO- } \\
\text { DAS score, mean } \\
\text { (SD) }\end{array}$ & $37.1(17.0)$ & $31.0(14.9)$ & 28.1 (12.8) & $\mid \begin{array}{l}F=9.8 \\
(2 ; 360)\end{array}$ & $<0.001$ \\
\hline $\begin{array}{l}\text { No. of chronic } \\
\text { diseases, mean (SD) }\end{array}$ & $2.4(1.6)$ & $1.9(1.4)$ & $2.0(1.3)$ & $\begin{array}{l}F=4.4 \\
(2 ; 369)\end{array}$ & 0.013 \\
\hline \multicolumn{6}{|l|}{$\begin{array}{l}\text { Psychological } \\
\text { variables }\end{array}$} \\
\hline $\begin{array}{l}\text { Cognitive function, } \\
\text { MMSE score, mean } \\
\text { (SD) }\end{array}$ & $27.3(2.3)$ & 27.9 (1.8) & $28.0(1.6)$ & $\mid \begin{array}{l}F=4.8 \\
(2 ; 369)\end{array}$ & 0.009 \\
\hline \begin{tabular}{|l} 
Severity of \\
depressive \\
symptoms, IDS-SR \\
score, mean (SD) \\
\end{tabular} & 32.9 (13.9) & $27.4(12.3)$ & $30.2(11.4)$ & $\begin{array}{l}F=6.9 \\
(2 ; 369)\end{array}$ & 0.001 \\
\hline $\begin{array}{l}\text { Anxiety symptoms, } \\
\text { BAI score, mean } \\
\text { (SD) } \\
\end{array}$ & 19.4 (13.1) & $16.4(10.3)$ & $15.7(9.4)$ & $\mid \begin{array}{l}F=3.4 \\
(2 ; 345)\end{array}$ & 0.034 \\
\hline $\begin{array}{l}\text { Insomnia, WHIRS } \\
\text { score, mean (SD) }\end{array}$ & $11.6(5.6)$ & $9.7(5.4)$ & $10.2(5.5)$ & $\begin{array}{l}F=4.4 \\
(2 ; 356)\end{array}$ & 0.014 \\
\hline $\begin{array}{l}\text { Loneliness, } \\
\text { Loneliness and } \\
\text { Affiliation Scale } \\
\text { score, mean (SD) }\end{array}$ & $7.2(3.2)$ & $6.4(3.7)$ & $6.0(3.4)$ & $\begin{array}{l}F=3.1 \\
(2 ; 346)\end{array}$ & 0.045 \\
\hline $\begin{array}{l}\text { Childhood trauma } \\
\text { index, mean (SD) }\end{array}$ & $0.90(1.1)$ & $1.01(1.2)$ & $1.32(1.3)$ & $\begin{array}{l}F=3.1 \\
(2 ; 367)\end{array}$ & 0.048 \\
\hline
\end{tabular}

Notes: BAI: Beck Anxiety Inventory; MMSE: Mini-Mental State Examination; IDS-SR: Inventory of Depressive Symptoms-Self-Report; SD: standard deviation; WHIRS: Women's Health Initiative Insomnia Rating Scale; WHO-DAS: WHO-Disability Assessment Schedule.

${ }^{A} \mathrm{p}$ value for categorical variables: Pearson's $\chi^{2}$ test; for continuous variables: analysis of variance. 
Table 2. : Correlates of Abstinence and At-Risk Drinking in Depressed Older Adults: Multivariate Analysis $(\mathrm{N}=373)$

\begin{tabular}{|c|c|c|c|c|}
\hline & \multicolumn{2}{|c|}{$\begin{array}{c}\text { Abstinence }(n= \\
150)\end{array}$} & \multicolumn{2}{|c|}{$\begin{array}{l}\text { At-Risk Drinking } \\
\quad(n=71)\end{array}$} \\
\hline & $\begin{array}{l}\text { Odds } \\
\text { Ratio }\end{array}$ & $\begin{array}{c}95 \% \\
\text { CI }\end{array}$ & $\begin{array}{l}\text { Odds } \\
\text { Ratio }\end{array}$ & $95 \% \mathrm{CI}$ \\
\hline Female gender & 1.41 & $\begin{array}{l}0.83- \\
2.40\end{array}$ & 0.62 & $\begin{array}{l}0.33- \\
1.16 \\
\end{array}$ \\
\hline Social support ( $\geq 2$ confidants) & $0.52^{\mathrm{a}}$ & $\mid \begin{array}{l}0.31- \\
0.88\end{array}$ & $0.49^{\mathrm{a}}$ & $\begin{array}{l}0.26- \\
0.92\end{array}$ \\
\hline Use of antidepressants & $0.53^{\mathrm{a}}$ & $\begin{array}{l}0.30- \\
0.95\end{array}$ & 1.08 & $\begin{array}{l}0.53- \\
2.20\end{array}$ \\
\hline Frequent use of benzodiazepines & $2.36^{\mathrm{b}}$ & $\begin{array}{l}1.41- \\
3.93\end{array}$ & 0.68 & $\begin{array}{l}0.34- \\
1.37 \\
\end{array}$ \\
\hline Smoking & 1.02 & $\begin{array}{l}0.56- \\
1.84\end{array}$ & $3.59^{c}$ & $\begin{array}{l}1.87- \\
6.86 \\
\end{array}$ \\
\hline $\begin{array}{l}\text { Functional limitations (WHO-DAS } \\
\text { score) }\end{array}$ & 1.01 & $\begin{array}{l}0.99- \\
1.03\end{array}$ & $0.96^{\mathrm{b}}$ & $\begin{array}{l}0.93- \\
0.99 \\
\end{array}$ \\
\hline Cognitive function (MMSE score) & $0.87^{\mathrm{a}}$ & $\begin{array}{l}0.77- \\
0.99\end{array}$ & 1.02 & $\begin{array}{l}0.85- \\
1.21 \\
\end{array}$ \\
\hline $\begin{array}{l}\text { Severity of depressive symptoms } \\
\text { (IDS-SR score) }\end{array}$ & 1.03 & $\begin{array}{l}1.00- \\
1.05\end{array}$ & $1.05^{\mathrm{b}}$ & $\begin{array}{l}1.01- \\
1.09 \\
\end{array}$ \\
\hline Childhood trauma index & 0.81 & $\begin{array}{l}0.65- \\
1.01\end{array}$ & 1.21 & $\begin{array}{l}0.93- \\
1.56 \\
\end{array}$ \\
\hline
\end{tabular}

Notes: Multinomial logistic regression analysis was conducted after multiple imputation of missing values. The reference category for the dependent variable is moderate alcohol consumption (Alcohol Use Disorders Identification Test [AUDIT] scores 1-4). Significance test $=$ Wald $\chi^{2}, d f=1$ for all analyses. CI: confidence interval; IDS-SR: Inventory of Depressive Symptoms-Self-Report; MMSE: Mini-Mental State Examination; WHODAS: WHO-Disability Assessment Schedule.

${ }^{A} \mathrm{p}<0.05$.

${ }_{\mathrm{B}}^{\mathrm{p}}<0.01$.

${ }^{\mathrm{C}} \mathrm{p}<0.001$. 